\title{
2 抵抗モデルによる温度予測とその誤差要因に関する考察
}

\author{
西 剛伺*
}

\section{Temperature Prediction with Two-Resistor Model and Consideration of The Cause of Its Prediction Error}

Koji NISHI*

*日本 AMD 株式会社エンベデットセールス（７ 100-0005＼cjkstart東京都千代田区丸の内 1-8-3 丸の内トラストタワー本館 10F）
*Embedded Sales, AMD Japan Ltd. (Marunouchi Trust Tower Main Building 10F, 1-8-3 Marunouchi, Chiyoda-ku, Tokyo 100-0005)

\section{1. はじめに}

2 抵抗モデルは CTM (Compact Thermal Model) $)^{1)}$ の 1 つ で, 熱回路網や 3 次元熱流体シミュレーションッール内で 使用することで，マイクロプロセッサを含む半導体のホッ トスポット温度（以下， ジャンクション温度）を予測する ことができるものである。2 抵抗モデルは, その表現がシ ンプルで概念として分かり易く, 電子機器の熱設計におい て広く使用されている。しかし，2 抵抗モデルは, JEDEC

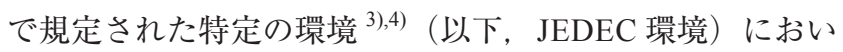
て測定，もしくは同等の設定でシミュレーションを実施し た結果から算出されるため, 適用する実装環境によっては 大きな温度予測誤差が生じてしまう 2),5)ことが知られてい る。また，近年では, CPU (Central Processing Unit) のマル チコア化, GPU (Graphics Processing Unit) や I/O (Input Output) を混載した SOC (System On a Chip) 化により, マイ クロプロセッサのシリコンダイ回路面における発熱は一様 であるとは言い難いが，2 抵抗モデルでは，シリコンダイ 回路面における発熱を一様と仮定してその值が算出される ことが多いのが現状である。そこで，本稿では，ノート ブック型パーソナルコンピュータ（以下， PC）やタブレッ トデバイス向けのマイクロプロセッサ ${ }^{6), 7)}$ に採用されてい る Fig. 1 に示すマイクロプロセッサパッケージをターゲッ トとして, 放熱機構の種類およびマザーボードサイズと いった実装環境, シリコンダイ回路面における発熱分布の 違いによって，2 抵抗モデルの值がどのように変動し，温
度予測誤差につながるか検証，考察する。

\section{2 抵抗モデルの定義と使用方法}

本稿で対象とするマイクロプロセッサは, Fig. 1 に示す ように，パッケージ上面中央に配置されたシリコンダイは モールドされておらず，その上面にサーマルグリースなど の TIM (Thermal Interface Material) を塗布して, 放熱機構を 装着する。また， BGA (Ball Grid Array) タイプのパッケー ジを採用しており，パッケージ底面にははんだボールが多 数配置され，マザーボード上に実装される。マイクロプロ セッサは, シリコンダイ底面近傍の回路面で発熱し, その 熱はシリコンダイから放熱機構を介する経路（以下，上方 の伝熱経路）とサブストレートを介してマザーボードに至 る経路（以下，下方の伝熱経路）に分かれて流れる (Fig. 2)。 2 抵抗モデルは, ジャンクションーケース間の熱抵抗 $\theta_{J C t o p}$ およびジャンクションーボード間の熱抵抗 $\theta_{J B}$ の組と して定義される。 $\theta_{J C t o p}, \theta_{J B}$ は以下の式から求めることが できる。

$$
\begin{gathered}
\theta_{J \text { Ctop }}=\frac{T_{J}-T_{\text {Ctop }}}{\dot{Q}_{\text {Upper }}} \\
\theta_{J B}=\frac{T_{J}-T_{B}}{\dot{Q}_{\text {Lower }}}
\end{gathered}
$$

ここで, $T_{J}$ は，シリコンダイ回路面のホットスポットの温 度であり，いわゆるジャンクション温度である。 $T_{C t o p}$ は パッケージ上面中心のケース温度であり, 本稿で扱うマイ クロプロセッサパッケージの場合, シリコンダイ上面中心

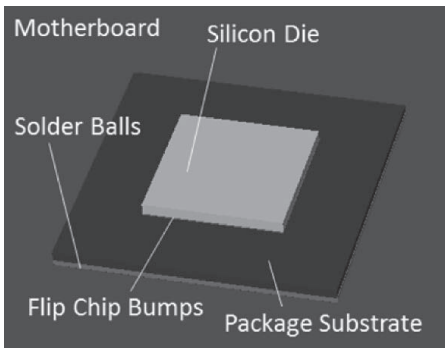

Fig. 1 Microprocessor package on motherboard

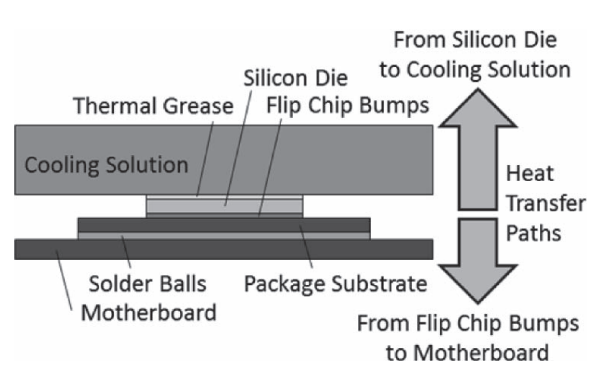

Fig. 2 Side view of the microprocessor system 


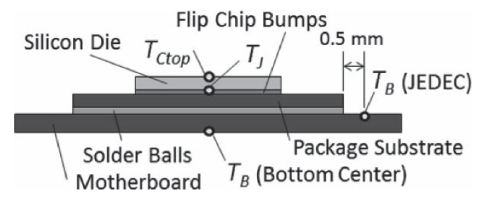

Fig. 3 Temperature points for two-resistor model

の温度である。 $T_{B}$ は, マイクロプロセッサパッケージ本体 の長辺中間点から $1 \mathrm{~mm}$ 以内の点におけるボード温度であ る $^{2)}$ 。本稿では, シリコンダイの発熱分布に偏りがある ケースも取り扱うため, 各辺中心から $0.5 \mathrm{~mm}$ 離れたマザー ボード上面 4 点の平均温度（以下, JEDEC）を $T_{B}$ とする。 なお， $T_{B}$ にはJEDECによる定義の他, 慣習的に, マイク ロプロセッサパッケージ真下のマザーボード底面中心の温 度（以下, Bottom Center) を $T_{B}$ とすることもあるが, 本稿 では，JEDECによる定義に焦点を当てて議論する。Fig. 3 にこれらの温度点を示す。 $\dot{Q}_{U p p e r}, \dot{Q}_{\text {Lower }}$ はそれぞれマイク ロプロセッサの上方および下方の伝熱経路に流れる伝熱量 である。

2 抵抗モデルは, 熱回路網もしくは 3 次元熱流体シミュ レーションツールとともに使用できる。ここで, 熱回路網 とは, 線形電気回路と部材の熱特性の類似性を利用して, 電気回路網の理論の一部を熱に適用したものである。電気 回路におけるオームの法則は, 電気抵抗 $R$ を直流電圧源 $E$ に接続して電流 $I$ が流れる際，以下の関係が成り立つ。

$$
I=\frac{E}{R}
$$

一方, 熱回路の場合にも, 熱抵抗 $\theta$ の部材に温度差 $\Delta T$ が 生じているとき，そこに流れる伝熱量 $\dot{Q}$ との間に以下の関 係が成り立つ。

$$
\dot{Q}=\frac{\Delta T}{\theta}
$$

つまり, 伝熱量 $\dot{Q}$ は電流 $I$, 温度差 $\Delta T$ は電位差 $E$, 熱抵抗 $\theta$ は電気抵抗 $R$ に対応する。キルヒホッフの法則も適用で きるため, 伝熱経路を複数の熱抵抗を接続して熱回路網と して表現し, 回路内での温度差を求めることで, 目的温度 を算出することができる。

2 抵抗モデルを熱回路網で使用する場合には, Fig. 4 (a) に示すマイクロプロセッサパッケージ外部の伝熱経路の熱 抵抗 $\theta_{C A}, \theta_{B A}$ および周囲温度 $T_{\text {Ambient-Upper }}, T_{\text {Ambient-Lower }}$ を入 手し, 以下の連立方程式を解いて, $T_{J}$ を求める。

$$
\begin{aligned}
T_{J} & =\left(\theta_{J C t o p}+\theta_{C A}\right) \cdot \dot{Q}_{\text {Upper }}+T_{\text {Ambient-Upper }} \\
& =\left(\theta_{J B}+\theta_{B A}\right) \cdot \dot{Q}_{\text {Lower }}+T_{\text {Ambient-Lower }} \\
P & =\dot{Q}_{\text {Upper }}+\dot{Q}_{\text {Lower }}
\end{aligned}
$$

ここで, $P$ はマイクロプロセッサの発熱量である。一方, 2 抵抗モデルを 3 次元熱流体シミュレーションツールで使 用する場合には，マイクロプロセッサパッケージ内部は熱 回路網の場合と同じであるが，マイクロプロセッサパッ ケージの外形サイズと等しい直方体ブロックとしてモデル

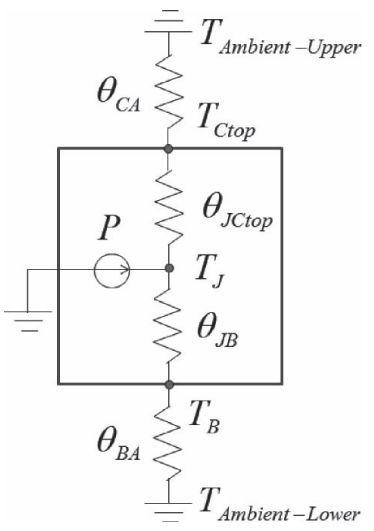

(a) Thermal network with JEDEC two-resistor model

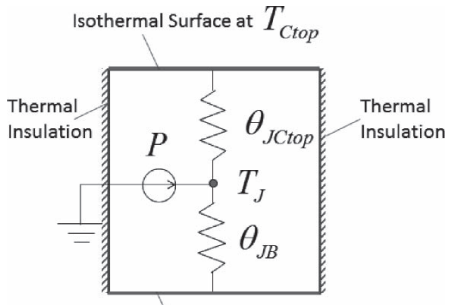

Isothermal Surface at $T_{B}$

(b) Computational fluid dynamics simulation model of JEDEC tworesistor model

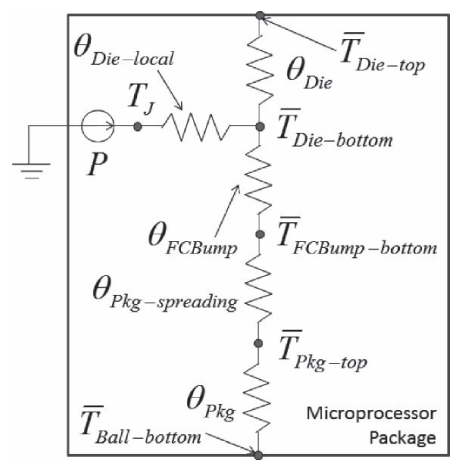

(c) One-dimensional thermal network of microprocessor package with average temperature nodes

\section{Fig. 4 Thermal network construction}

化し, Fig. 4 (b) に示すようにマイクロプロセッサパッケー ジ境界の側面は断熱，上面，底面は等温面として扱う。

\section{3 次元熱伝導シミュレーションによる検証}

まず最初に，実装環境の違いによって 2 抵抗モデルの $\theta_{J C t o p}$ および $\theta_{J B}$ にどの程度影響があるか検証するため, Table 1 に示す JEDEC 環境とマイクロプロセッサが実際の 電子機器筐体内で使用される環境（以下，実システム環境） について 3 次元熱伝導シミュレーションを実施する。実シス テム環境については, Fig. 5 (a) のファン付きヒートシンク を放熱機構として採用し，マザーボードサイズが $150 \mathrm{~mm} \times$ $150 \mathrm{~mm} \times 1.6 \mathrm{~mm}$ であるモデルをベースケース (Heat Sink Base Case) として, Fig. 5 (b) および (c) に示した放熱機構に 変更したモデル, マザーボードサイズを変更したモデル， マイクロプロセッサのシリコンダイ底面における発熱分布 を変えたモデルによる複数のテストケースを用意した。議 論を容易にするため, マイクロプロセッサには，実製品と は直接関係しない単純な構成，発熱分布を有するモデルを 使用する (Table 2)。また, JEDEC 環境以外のモデル領域お よび境界条件を Table 3 に示す。発熱分布を変えたテスト ケースでは，シリコンダイ底面を 2 つの領域に分け，指定 した割合で領域ごとに一様発熱するものとする (Fig. 6)。 
Table 1. Simulation cases for two-resistor model investigation

\begin{tabular}{|c|c|c|c|c|}
\hline Test Name & Test Cases & Cooling Solution & Motherboard Size & Heat Distribution \\
\hline JEDEC Definition & - & Cold Plates & JEDEC Defined & \multirow{7}{*}{ Uniform } \\
\hline Heat Sink Base Case & - & Heat Sink Fan & \multirow{3}{*}{$150 \mathrm{~mm} \times 150 \mathrm{~mm}$} & \\
\hline \multirow{2}{*}{ Cooling Solution } & RHE & RHE & & \\
\hline & Heat Spreader & Heat Spreader & & \\
\hline \multirow{3}{*}{ Motherboard } & $100 \times 100$ & \multirow{5}{*}{ Heat Sink Fan } & $100 \mathrm{~mm} \times 100 \mathrm{~mm}$ & \\
\hline & $200 \times 200$ & & $200 \mathrm{~mm} \times 200 \mathrm{~mm}$ & \\
\hline & $300 \times 300$ & & $300 \mathrm{~mm} \times 300 \mathrm{~mm}$ & \\
\hline \multirow{2}{*}{ Heat Distribution } & $50 \% / 50 \%$ & & \multirow{2}{*}{$150 \mathrm{~mm} \times 150 \mathrm{~mm}$} & $50 \% / 50 \%$ \\
\hline & $75 \% / 25 \%$ & & & $75 \% / 25 \%$ \\
\hline
\end{tabular}

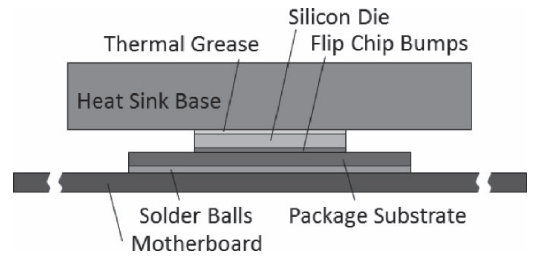

(a) Heat sink fan

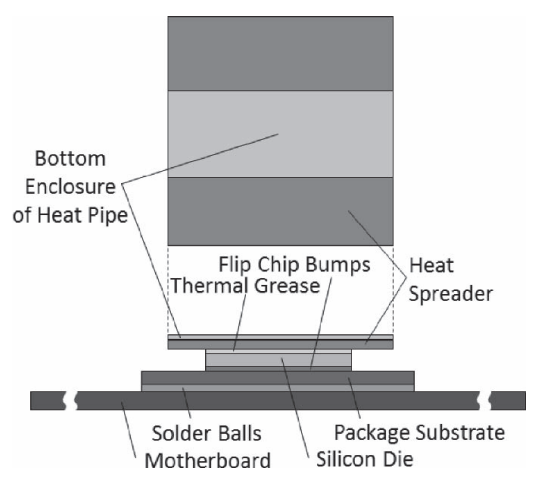

(b) RHE (remote heat exchanger)

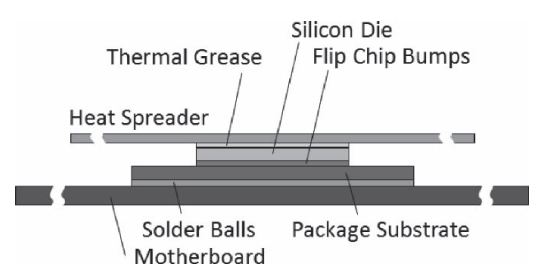

(c) Heat spreader

Fig. 5 Simulation models with different cooling solution

Table 2. Dimension and thermal conductivity of generic microprocessor package model

\begin{tabular}{l|c|c}
\hline \multicolumn{1}{c|}{ Part } & Dimension & Thermal Conductivity \\
\hline $\begin{array}{l}\text { Silicon } \\
\text { Die }\end{array}$ & $10 \times 10 \times 0.80 \mathrm{~mm}$ & $120 \mathrm{~W} / \mathrm{mK}$ \\
\hline $\begin{array}{l}\text { Flip Chip } \\
\text { Bumps }\end{array}$ & $10 \times 10 \times 0.10 \mathrm{~mm}$ & $10 \mathrm{~W} / \mathrm{mK}$ \\
\hline $\begin{array}{l}\text { Package } \\
\text { Substrate }\end{array}$ & $20 \times 20 \times 0.70 \mathrm{~mm}$ & $\begin{array}{c}30 \mathrm{~W} / \mathrm{mK} \text { (Horizontal) } \\
1.0 \mathrm{~W} / \mathrm{mK} \text { (Vertical) }\end{array}$ \\
\hline $\begin{array}{l}\text { Solder } \\
\text { Balls }\end{array}$ & $20 \times 20 \times 0.40 \mathrm{~mm}$ & $\begin{array}{c}0.026 \mathrm{~W} / \mathrm{mK} \text { (Horizontal) } \\
10 \mathrm{~W} / \mathrm{mK} \text { (Vertical) }\end{array}$ \\
\hline
\end{tabular}

50\%/50\%のテストケースでは高発熱エリア, 低発熱エリア それぞれに全体の $50 \%$ ずつ発熱を与える。一方，75\%/25\% のテストケースでは高発熱エリアに全体の $75 \%$, 低発熱エ リアに全体の $25 \%$ の発熱を与える。 $T_{J}$ は, 発熱分布を変え たテストケースでは高発熱エリア中心とする。それ以外の
Table 3. Construction and boundary conditions of simulation model

\begin{tabular}{|c|c|c|c|}
\hline $\begin{array}{l}\text { Cooling } \\
\text { Solution }\end{array}$ & Heat Sink Fan & RHE & Heat Spreader \\
\hline \multicolumn{4}{|c|}{ Cooling Solution (Upper Side Path) } \\
\hline Dimension & $50 \times 50 \times 5 \mathrm{~mm}$ & $\begin{array}{r}15 \times 15 \times 0.8 \mathrm{~mm} \\
+7 \times 15 \times 0.3 \mathrm{~mm}\end{array}$ & $100 \times 100 \times 0.8 \mathrm{~mm}$ \\
\hline $\begin{array}{l}\text { Thermal } \\
\text { Conductivity }\end{array}$ & $209 \mathrm{~W} / \mathrm{mK}$ & $398 \mathrm{~W} / \mathrm{mK}$ & $225 \mathrm{~W} / \mathrm{mK}$ \\
\hline $\begin{array}{l}\text { Heat Transfer } \\
\text { Coefficient }\end{array}$ & $\begin{array}{l}200 \mathrm{~W} / \mathrm{m}^{2} \mathrm{~K} \\
\text { (Upper Only) }\end{array}$ & $\begin{array}{l}15,000 \mathrm{~W} / \mathrm{m}^{2} \mathrm{~K} \\
\left(\text { Upper Only }^{*}\right)\end{array}$ & $\begin{array}{c}6.5 \mathrm{~W} / \mathrm{m}^{2} \mathrm{~K} \text { (Upper) } \\
3.25 \mathrm{~W} / \mathrm{m}^{2} \mathrm{~K} \text { (Lower) }\end{array}$ \\
\hline $\begin{array}{l}\text { Base } \\
\text { Temperature }\end{array}$ & Room Ambient & $\begin{array}{l}\text { Room Ambient } \\
+35 \text { deg C }\end{array}$ & Room Ambient \\
\hline \multicolumn{4}{|c|}{ Motherboard (Lower Side Path) } \\
\hline Dimension & \multicolumn{3}{|c|}{$100 \times 100,150 \times 150,200 \times 200,300 \times 300 \times 1.6 \mathrm{~mm}$} \\
\hline $\begin{array}{l}\text { Thermal } \\
\text { Conductivity }\end{array}$ & \multicolumn{3}{|c|}{$30 \mathrm{~W} / \mathrm{mK}$ (Horizontal), $0.45 \mathrm{~W} / \mathrm{mK}$ (Vertical) } \\
\hline $\begin{array}{l}\text { Heat Transfer } \\
\text { Coefficient }\end{array}$ & \multicolumn{3}{|c|}{$\begin{array}{c}4.5 \mathrm{~W} / \mathrm{m}^{2} \mathrm{~K} \text { (Upper) } \\
2.25 \mathrm{~W} / \mathrm{m}^{2} \mathrm{~K} \text { (Lower) }\end{array}$} \\
\hline $\begin{array}{l}\text { Base } \\
\text { Temperature }\end{array}$ & \multicolumn{3}{|c|}{ Room Ambient } \\
\hline
\end{tabular}

* Applied to "Heat Pipe" area $(7 \times 15 \mathrm{~mm})$ only.

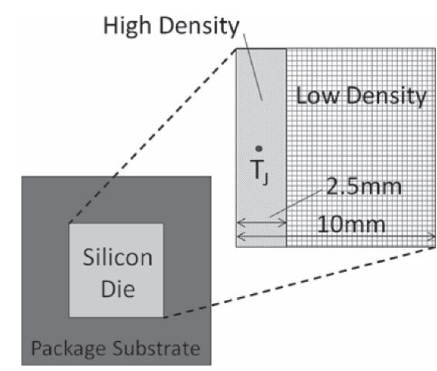

Fig. 6 Top view of microprocessor package and non-uniform heat distribution

テストケースでは, シリコンダイ底面における発熱を一様 とし， $T_{J}$ はシリコンダイ底面中心の温度とする。

熱伝導シミュレーションの結果として得られた各テスト ケースの $\theta_{J \text { Ctop }}$ と $\theta_{J B}$ の分布を Fig. 7 に示す。マイクロプロ セッサのシリコンダイ底面における発熱が一様である場 合， $\theta_{\text {JCtop }}$ は，JEDEC 環境含め，テストケースによらずほ ぼ同じ值を採るが， $\theta_{J B}$ は放熱機構やマザーボードサイズの 違いにより変動することが分かる。特に，JEDEC 環境にお ける $\theta_{J B}$ は他のテストケースと比較してやや小さい值を採 る。一方, 発熱分布を変えたテストケースでは, 発熱分布 の偏りが大きくなるほど, $\theta_{J C t o p}, \theta_{J B}$ ともに JEDEC 環境よ り大きな值を採ることが分かる。

続いて, $\theta_{J C t o p}$ および $\theta_{J B}$ の值の変動について詳細に議論 


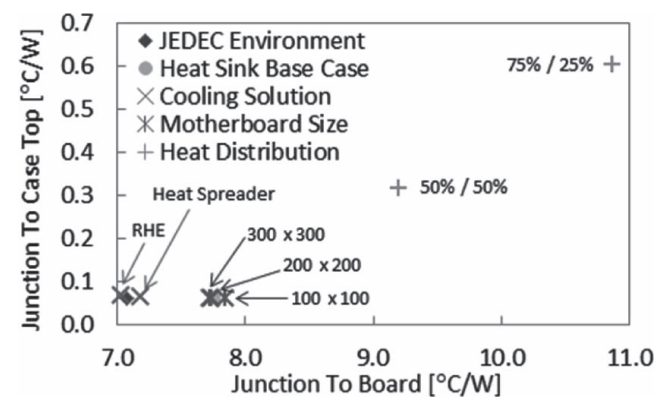

Fig. 7 Two-resister value comparison

するため, JEDEC 環境およびベースケースにおけるマイク ロプロセッサパッケージを構成する個々の熱抵抗を比較す ることとした。Fig. 8 にJEDEC 環境における 2 抵抗モデル の熱抵抗值と JEDEC 環境およびベースケースにおけるマイ クロプロセッサパッケージを構成する熱抵抗の内訳を示 す。マイクロプロセッサパッケージを構成する個々の熱抵 抗は, Fig. 4 (c) に示す平均温度をノードとするマイクロプ ロセッサパッケージの熱回路網 ${ }^{8)}$, 9) を構成する熱抵抗であ る。本熱回路網は, 熱の流れと温度差の関係をエネルギ保 存則から導き直したものであり, 各部材における温度上昇 要因を個々の熱抵抗として表現することができる。以下, マイクロプロセッサパッケージを構成する熱抵抗について 説明する。

マイクロプロセッサは, シリコンダイ底面の回路面で発 熱する。一様発熱の場合を含め, シリコンダイの温度は厳 密には一様ではなく, ある程度の温度勾配がある。それを 表すのがシリコンダイにおける局所熱抵抗 $\theta_{\text {Die-local }}$ であり, 以下の式で定義される。

$$
\theta_{\text {Die-local }}=\frac{T_{J}-\bar{T}_{\text {Die-bottom }}}{P}
$$

ここで， $\bar{T}_{\text {Die-bottom }}$ はシリコンダイ底面の平均温度である。 Fig. 8 に示す通り， $\theta_{\text {Die-local }}$ はテストケースによって值が変 動する。上方の伝熱経路に関しては, 熱はシリコンダイ底 面 $\left(\bar{T}_{\text {Die-bottom }}\right)$ からシリコンダイ $\left(\theta_{D i e}\right)$ を介してシリコンダイ 上面 $\left(\bar{T}_{D i e-t o p}\right)$ に至る。そのため, 上方の伝熱経路に属する マイクロプロセッサパッケージの総抵抗は $\theta_{\text {Die-local }}$ と $\theta_{D i e}$ の 和である。 $\theta_{D i e}$ は以下の式から求めることができる。

$$
\theta_{\text {metrial }}=\frac{l}{k_{\text {material }} A}
$$

ここで, $l$ は部材の厚み, $k_{\text {material }}$ は部材の熱伝導率, $A$ は部 材の断面積である。これらの值は伝熱経路の構成とは関係 なく, その部材の寸法および熱伝導率のみで一意に定ま る。そのため, 上方の伝熱経路に属するマイクロプロセッ サパッケージの総熱抵抗は $\theta_{\text {Dielocal }}$ によって変動することに なる。一方, $\theta_{J C t o p}$ は $\theta_{D i e}$ に近い值を採っている。つまり, $\theta_{J C t o p}$ は $\theta_{\text {Die-local }}$ の分だけ実際より熱抵抗值を小さく見積っ ていることになる。

下方の伝熱経路に関しては, シリコンダイ底面 $\left(\bar{T}_{D i e-b o t t o m}\right)$

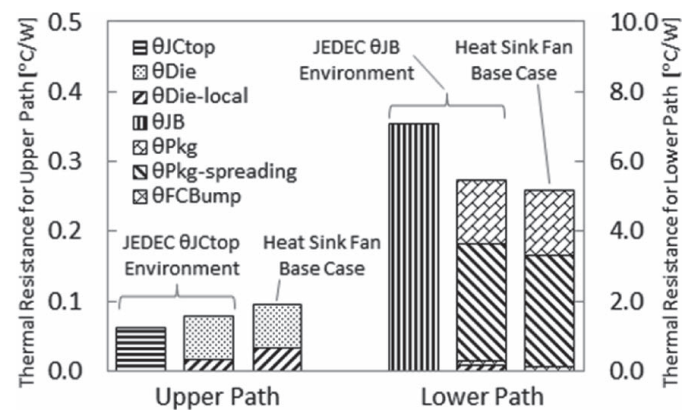

Fig. 8 Thermal resistance composition along upper and lower heat transfer paths

からフリップチップバンプ $\left(\theta_{F C B u m p}\right)$ を通った後, パッケー ジサブストレートがフリップチップバンプ層より大きいた め, そこで熱が拡がる際に温度差が生じる。その温度差を 表す熱抵抗が拡大熱抵抗 $\left(\theta_{\text {Pkg-spreading }}\right)$ である。拡大熱抵抗 は，以下の式で定義される。

$$
\theta_{\text {Pkg-spreading }}=\frac{\bar{T}_{F C \text { Bump-bottom }}-\bar{T}_{\text {Pkg-top }}}{\dot{Q}_{\text {Lower }}}
$$

ここで, $\bar{T}_{F C \text { Bump-bottom }}$ はフリップチップバンプ層底面の平均 温度, $\bar{T}_{P k g-t o p}$ はパッケージサブストレート上面の平均温度 である。その後, 熱ははんだボールを含むパッケージ本体 $\left(\theta_{P k g}\right)$ を介して，はんだボール層底面 $\left(\bar{T}_{\text {Ball-bottom }}\right)$ に至る。つ まり，下方の伝熱経路に属するマイクロプロセッサパッ ケージの総熱抵抗は $\theta_{\text {Die-local }}, \theta_{F C \text { Bump }}, \theta_{\text {Pkg-spreading, }} \theta_{P k g}$ の和 である。 $\theta_{F C B u m p}$ および $\theta_{P k g}$ (に含まれるパッケージサブス トレートおよびはんだボール層の熱抵抗）は，式 (8) から 求めることができ，その部材の寸法および熱伝導率のみで 一意に定まる。一方， $\theta_{\text {Die-local }}$ および $\theta_{\text {Pkg-spreading }}$ は Fig. 8 に 示す通り，テストケースによって僅かではあるが值が変動 する。また，JEDEC 環境で得られた $\theta_{J B}$ は，下方の伝熱経 路に属するマイクロプロセッサパッケージの総熱抵抗より も大きい值を採る。

上記に加えて，2 抵抗モデルを 3 次元熱流体シミュレー ションッールに適用する場合, マイクロプロセッサパッ ケージの上面および底面における温度分布を一様として扱 うため, それぞれの伝熱経路の下流において熱の流れを適 切に表現できず，さらに温度予測誤差が大きくなる。

\section{2 抵抗モデルに関する考察}

マイクロプロセッサのシリコンダイ底面における発熱分 布が一様である場合, $\theta_{J C t o p}$ は放熱機構, マザーボードサイ ズの違いによらず，ほぼ一定であり，式 (8)で示される熱 抵抗值に近い值を採る。一方, 発熱分布が一様でない場 合, $\theta_{J C t o p}$ は一様発熱の場合と比べて大きな值を採ることが 分かった。 $\theta_{\text {JCtop }}$ は特定の 2 点間で定義される熱抵抗であ り, 式 (1)の分子の温度差はその 2 点間に流れる局所的な 熱流束によって決まるのに対して，分母にはその伝熱経路 に流れる総伝熱量を用いている。そのため，2 点間に流れ 
る局所的な熱流束が変化すると, 分母, 分子のバランスが 崩れ, 值が変動する。つまり, 一様発熱の場合には, 熱流 束もほぼ一様であるため, $\theta_{J C t o p}$ はシリコンダイの熱抵抗值 に近いほぼ一定の值を採るが，発熱分布が一様でない場合 には, 大きく異なる值を採る可能性があり, 注意が必要で ある。一例を示すと, マイクロプロセッサが $20 \mathrm{~W}$ 発熱時, $75 \% / 25 \%$ のテストケースでは上方の伝熱経路に約 $17.7 \mathrm{~W}$ の熱が流れる。このときJEDEC 環境やベースケースにおけ る $\theta_{J C \text { top }}$ 值を $75 \% / 25 \%$ のテストケースに用いると， $10^{\circ} \mathrm{C}$ 程 度 $T_{J}$ を低く見積もってしまうことになる。

$\theta_{J B}$ は, 放熱機構, マザーボードサイズ, 発熱分布の違い のいずれが変化しても值が変動する。そのため, JEDEC 環 境で取得した $\theta_{J B}$ 值をそれ以外の環境における温度予測に 用いると予測誤差を生じる可能性がある。また， $\theta_{J B}$ は下方 の伝熱経路に属するマイクロプロセッサパッケージの総抵 抗より大きな值を採る。これは $T_{B}$ がパッケージ底面温度で はなく，マザーボード表面の特定点を $T_{B}$ としているため, マザーボードに扔ける拡大熱抵抗や部材の熱抵抗の一部を 取り込んでしまっているためであると考えられる。また, $\theta_{J B}$ についても $\theta_{J C t o p}$ と同様に式 (2) の分子, 分母のバラン スによって值が変動する。その傾向は発熱分布の偏りが大 きいほど顕著である。

$\theta_{J C T o p}$ と $\theta_{J B}$ が変動する場合, 同様に $T_{C T o p}$ と環境温度, $T_{B}$ と環境温度の間に存在する熱抵抗も変動するため, 異なる 条件から得られた熱抵抗を組み合わせて温度を予測する と, さらに大きな予測誤差を生じる可能性がある。この問 題は 2 抵抗モデルに限らず, 特定点をノードとして構成す る従来の 1 次元の熱回路網に共通して存在するものであ り, 注意が必要である。

\section{5. 結 言}

本稿では, ノートブック型 PC およびタブレットデバイ スで採用されるマイクロプロセッサを対象として，3 次元 熱伝導シミュレーションの結果から伝熱経路各部における 熱抵抗值を求め, 伝熱経路の構成の違いによる 2 抵抗モデ ルの値の変動と誤差要因について考察した。得られた知見 は以下の通りである。

- 2 抵抗モデルでは, 熱の流れを 1 次元的に扱っている が, 熱抵抗值を固定值として扱っており，JEDEC 環境で 取得した熱抵抗値をそれ以外の環境に適用して温度予測 を実施すると誤差を生じる。

一シリコンダイにおける発熱が一様の場合, 放熱機構, マ ザーボードサイズといった実装環境によらず， $\theta_{J C t o p}$ は JEDEC 環境とほぼ同じ值を採り，その值はシリコンダイ の熱抵抗に近い。

一シリコンダイにおける発熱が一様でない場合， $\theta_{J C t o p}$ は一 様発熱であるJEDEC 環境に比べて大きな值を採る。その
值は発熱分布の偏りが大きくなるほど大きくなる。

一 $\theta_{J B}$ は放熱機構，マザーボードサイズ，シリコンダイに おける発熱分布のいずれが変化しても值が変動する。ま た， $\theta_{J B}$ は下方の伝熱経路に属するマイクロプロセッサ パッケージの総抵抗より大きな值を採る。これは $T_{B}$ が パッケージ底面温度ではなく、マザーボード表面の特定 点を $T_{B}$ としているため, マザーボードに扔ける拡大熱抵 抗や部材の熱抵抗の一部を取り込んでしまっているため であると考えられる。また，発熱分布を変えたテス卜 ケースでは, 発熱分布の偏りが大きくなるほど, $\theta_{J B}$ は大 きな值を採る。

(2015.1.20- 受理)

\section{文献}

1) JEDEC Standard: “Compact Thermal Model Overview," JESD151, JEDEC Solid State Technology Association, 2008

2) JEDEC Standard: “Two-Resistor Compact Thermal Model Guideline," JESD15-3, JEDEC Solid State Technology Association, 2008

3) JEDEC Standard: "Integrated Circuit Thermal Test Method Environmental Conditions - Junction-to-Board,” JESD51-8, Electronic Industries Alliance and JEDEC Solid State Technology Association, 1999

4) JEDEC Standard: "Guidelines for Reporting and Using Electronic Package Thermal Information,” JESD51-12, JEDEC Solid State Technology Association, 2005

5) “半導体製品におけるパッケージ熱特性ガイドライン, JEITA EDR-7336，電子情報技術産業協会技術レポート， 2010

6) "The worlds first combination of low-power CPU and advanced GPU intergrated into a single embedded device," Product Brief: AMD Embedded G-Series APU Platform, Publication \# 49282, 2013

7) Family 16 h Models 00h-0Fh AMD A-Series Mobile Accelerated Processor Product Data Sheet, Publication \# 52169, Rev 3.03, 2014

8) K. Nishi, T. Hatakeyama, and M. Ishizuka: “Steady and Transient Heat Transfer Analysis of The Microprocessor System Using OneDimensional Thermal Network," InterPACK2013, IPACK201373052, 2013

9) 西 剛伺, 畠山友行, 中川慎二, 石塚 勝: “半導体パッ ケージ向け 2 抵抗モデルに関する考察, ”E124, 日本伝熱シ ンポジウム 2014, 2014

西 剛伺 (にしこうじ) 著者紹介

1998 年早稲田大学理工学部卒業。2 000 年 3 月同大学大学院理工学研究 科修士課程修了。他の半導体メーカを経て 2005 年日本 AMD 株式会社入 社。現在，組み込み向けマイクロプロセッサ製品の技術サポートを担当。 